\title{
The Role of ICT in Social Inclusion: A Review of Literature
}

\author{
Muchiri Njoki ${ }^{1}$, Franklin Wabwoba ${ }^{2}$ \\ ${ }^{1}$ Dedan Kimathi University of Technology, Department of Information Technology, P.O BOX 657-10100, Nyeri, Kenya. \\ ${ }^{2}$ Kibabii University, School of Computing and Informatics, P.O. Box 1699—50200, BUNGOMA-KENYA.
}

\begin{abstract}
The questions we seek to answer in this paper are; Have ICT contributed to enhance social inclusion? Has use of ICT brought new forms of exclusion? And what is the way forward in using ICT for an inclusive society? Desk Top research was used. From the findings, one form of exclusion often leads to another, resulting to a cycle. a spanner and Nut Model was developed to show how Knowing which exclusion to reduce in order to break the cycle is critical in determining the type of ICT and how to apply it in order create an inclusive society.
\end{abstract}

Keywords: Digital Inclusion, Social Inclusion, ICT, Exclusion Cycle

Sponsorship: We appreciate the Study financial sponsorship by the National Council of Science Technology and Innovation (Kenya).

\section{Introduction}

"Poverty has multiple and complex causes. The poor are not just deprived of basic resources. They lack access to information that is vital to their lives and livelihoods: information about market prices for the goods they produce, about health, about the structure and services of public institutions, and about their rights. They lack political visibility and voice in the institutions and power relations that shape their lives. They lack access to knowledge, education and skills development that could improve their livelihoods. They often lack access to markets and institutions, both governmental and societal that could provide them with needed resources and services. They lack access to, and information about, income earning opportunities..." [1]

Social exclusion and inclusion concepts seek to address the human welfare crisis. Social inclusion is a discourse that emerged in response to failure of earlier developmental discourses such as poverty eradication [2]. These earlier discourses on social division's emphasized lack of adequate resources as responsible for poverty [2], leading to some members of society being disadvantaged and unable to -. achieve acceptable standards of well being and ... to participate in the customary activities of society..." [2] . The earlier discourses in a way, apportioned the blame on the victims, and fate, as the case may be, and somehow exonerating the society from the responsibility. They advocated providing relieve through free services and materials for the poor as a remedy to social divisions [2],[3].This was done mainly by churches, charitable organizations and sometimes the government.

Social inclusion discourse is assumed superior than the discourses it replaced due to its multidimensional nature [4]; [2] Overtime, it has become apparent that social welfare is not just about resources and poverty reduction [4]. Exclusion issues range from housing, job opportunities, right to vote, gender equality, access to education, safe energy, water, racial discrimination, access to services, people with special needs [4], [5] among many others. Pradhan [2] asserts that Social inclusion relates to a wide range of phenomena such as poverty, forms of deprivation, social, cultural and political disadvantages, and references different categories of excluded people [6]; [2].Deprivation and poverty goes beyond access to money, [5]. In my view, the beauty in exclusion inclusion debate is in the fact that the discourse does not blame the victim but rather seeks to fix the flaws that cause the exclusion within the society. As such, the society is held accountable for its policies and norms. It's important to acknowledge the involuntary aspect of exclusion.

A document by United Nations [3] on measuring social inclusion defines - Soial exclusion" as —...Te involuntary exclusion of individuals and groups from society's political, economic and societal processes, which prevents their full participation in the society in which they live..."

According to Allman [7] the need to belong is a fundamental human motivation. Belongingness is a basic human need that has led to inclusion and exclusion being used as reward and punishments in different societies and times in history. One of the social inclusion discourse goals is to achieve an inclusive society [3] where everyone has a right and a responsibility. One that -..rises above differences of race, gender, class, generation, geography..." and ensure equal opportunity no matter where one comes from [8].

When people are included they become responsible. It's in such societies that, when new challenges such as global warming arise, everyone contributes because they have a say, a right and a responsibility [3]. The alternative, which is exclusion, leads to ignorance, poverty, gender inequality, civil war and armed rebellion, especially where political exclusion is present among other calamities.

This paper seeks to establish how ICT have contributed to enhance social inclusion, any new forms of exclusion arising as results of ICT and way forward in using ICT for social exclusion.

\section{Volume 4 Issue 12, December 2015}




\section{International Journal of Science and Research (IJSR) \\ ISSN (Online): 2319-7064}

Index Copernicus Value (2013): 6.14 | Impact Factor (2014): 5.611

\subsection{Research Objectives}

a) to establish how ICT have contributed to enhance social inclusion,

b) to establish new forms of exclusion arising as results of ICT

c) suggest the way forward in using ICT for social inclusion

\subsection{Research Questions}

a) Have ICT contributed to enhance social inclusion?

b) Has use of ICT brought new forms of exclusion?

c) What is the way forward in using ICT for an inclusive society?

\section{Literatures Review}

\subsection{Social Inclusion and Exclusion Concepts}

It was in France that the term social exclusion was first used in the early 70 s to describe various categories of people such as - ...th mentally and physically disabled, the aged, abused children, single parents, marginal, asocial persons, 'misfits' ..." [2] among others who were not employable and thus socially insecure [9]; [2]. With time, new problems and social groups have been included in the redefinition of the term. The charity commission in England developed a guide for promotion of social inclusion activities back in the year 2001. The guide identifies factors that lead to isolation as the following;

-..unemployment, financial hardship, Age (youth or old age), ill health ( including disability), substance abuse, discrimination, poor education skills, family breakdown, poor housing and crime ( offender or victim)..." [10]

According Steyn [9] Social exclusion and inclusion concepts have different meaning to different scholars. He argues that different theoretical backgrounds and ideals lead to different perceptions of the social inclusion and exclusion concepts. This in turn leads to different approaches on how to handle social problems as well as how ICT is employed in enhancing social inclusion. The different views have one thing in common though, addressing the shortcomings of the vulnerable; with an aim of increasing their capabilities and opportunities for them to participate in the society they are in, and the ultimate goal being towards building an inclusive society [3].

Exclusion can be general or specific [2]. It can also be passive or active exclusion. Passive exclusion is not result from deliberate effort to cause deprivation but from factors such as poverty, disability or geographical location [6]; [18]; [19]; [20]; [21]. However, deliberate laws or policies that deprive people lead to active exclusion. How does exclusion lead to deprivation? Exclusion can also be viewed in terms of constitutive relevance or instrumental importance [2]. Social exclusion could be deprivation in itself (constitutive relevance) so is inability to access broad band internet. It could also lead to other deprivations. Lack of access to internet may lead missing opportunities to apply for jobs resulting to lack of employment which may lead to poverty (constitutive relevance).

\section{Methodology}

The methodology adopted was integrated Literature survey research approach [11] in this paper. To identify relevant research and other social inclusion activities, a traditional search was conducted using the key words social inclusion", -social exclusion" and -digital inclusion". This resulted in identification of key research papers, technical reports and literature related to social inclusion activities both in Africa and abroad, factors influencing inclusion and exclusion both globally and locally. A critical review of the selected literature addressing the study area was then conducted to identify the different way ICT have been used in inclusion activities, its effect and exclusion tendencies that have resulted from use of ICT. This data was analyzed to give a better view of how best to use ICT in social inclusion while still Reducing potential digital exclusion

\section{Exclusion Cycle}

Unlike earlier discourses, social inclusion addresses the welfare concerns by attempting to create a society for all [12]. In other words, there is an acknowledgement that addressing one aspect of oppression may not in itself solve poverty or protect people from being excluded [13] as social exclusion and inclusion concerns more dimensions of people's lives than just poverty [14] I submit however, the process of inclusion may start by addressing that one dimension. As mentioned earlier, social inclusion is multidimensional. One dimension of exclusion may lead to another, which may in turn lead yet to another eventually creating an exclusion cycle".

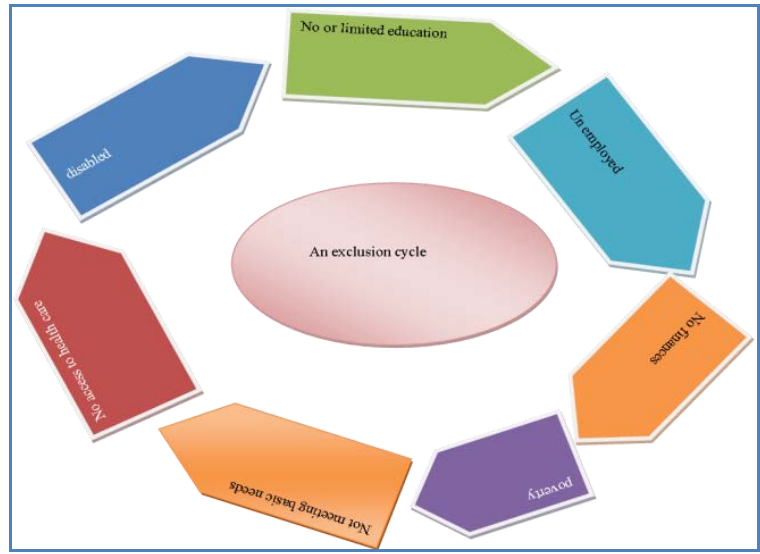

Figure 1: An Example of An Exclusion Cycle

Source: author

Fig1 shows an example of an exclusion cycle. The cycle could have started anywhere. Being poor limits access to basic amenities like health care. Poor health may lead to disabilities such as blindness. Disability requires special care and special education which is not affordable to the victim. This may as a result of discrimination, lack of facilities, or ignorance. This translates to low or no education qualifications which are a requirement for one to secure a job [15]. being unemployed may translate to lack of financial provision which is one of the contributors to health.

Rawal [14] asserts that -..meaning of social exclusion depends on the nature of the society, or the dominant model 


\section{International Journal of Science and Research (IJSR) \\ ISSN (Online): 2319-7064}

Index Copernicus Value (2013): 6.14 | Impact Factor (2014): 5.611

of the society from which exclusion occurs and it varies in meanings according to national and ideological contexts..." [14] As such the exclusion cycle may be different for different individuals or groups. To solve this problem, we thus need to identify where the cycle started and the path it has taken for each individual case. Picking the right exclusion to exclude would break the cycle. Providing affordable access to education for people living with disability, raising awareness and affirmative action for their employment would be one step in breaking the cycle. In ICT for instance, making phones, PCs and the internet affordable would create opportunities for many who are marginalized.

According to Sen's Capability approach [16], the welfare of human life can be analyzed in terms of individual capabilities and functioning. While the Functionings are achievements, the capabilities are the abilities to achieve them [17] Functionings are states of being and doing. It is what an individual is or is doing such as owning a mobile phone, transacting an e-service, being e-skilled, participating in elections, being malnutrition or being healthy. Capability on the other hand is the set of valuable functioning that a person has effective access to [18]. Here we look at what choices an individual has on what functioning to achieve. For instance, a person $\mathrm{Y}$ chooses to queue in the bank hall to withdraw money because the line in the ATM is equally long and besides he may enjoy a sitting break in the banking hall even as he waits for the queue to move. Another person $\mathrm{X}$ has to queue in the banking hall as well but because he is not able to use the ATM. The ATM's interface is designed in English for instance and would require her to input her PIN in order to complete the transaction. Person Y, being illiterate and English not being her first language, will have to disclose her PIN to a stranger and risk being fraud or cannot simply use the ATM. While X and Y are basically doing the same thing (functioning), $\mathrm{Y}$ is doing it more out of choice while $\mathrm{X}$ on the other hand is doing it more for lack of an alternative choice. $X$ has no ability to achieve an ATM transaction [19]. As a result of this inability, $X$ has to incur higher charges for over the counter withdraws, endure long queues in the banking hall, and may have to travel to the bank premises possibly leaving an ATM facility in her neighborhood. This is a clear case of inequality.

In other words, to find exclusion, we need to evaluate what capabilities or functionings the affected and the vulnerable group has been denied. Then find an alternative way of availing the same capabilities or functioning to the affected group. We seek to reduce if not eliminate the vulnerability of the affected.

To fight exclusion, the inclusion policies should be adopted. Most of the development policies in developed countries have been influenced by social inclusion concepts. Inclusion strategies include public access to services and resources, education for all, civic education, gender empowerment etc. The emerging of ICT and related technologies has with no doubt had a great influence in the modern society [18]. ICT has brought much capabilities and efficiencies not precedent before. And just like every other aspect of today's society has gone digital, social inclusion strategies have also integrated ICT.

\section{Role of ICT}

ICT and related technologies have given rise to new capabilities to the human race. As Smith puts it -.. Mobile phones constitute the basis for one of the greatest expansions of human capabilities in known history, and in a remarkably short timeframe. Furthermore, this expansion is expected to continue apace and, more likely, to accelerate..." [18] The ICT has continued to increase in capacity, mobility, accessibility and affordability [19]; [20]. The growth of ICT has affected every aspect of human life [19] -..virtually every aspect of our lives has a digital dimension" [21].

According to [1] - ..fl ICTs are to help address poverty, they need to be used to address real problems in sustainable ways..." Greenberg contends that the focus has to be in poverty and not ICT. We need to ask what need to be done and how does ICT come in. in other words, ICT is more of a tool than a need itself according to Greenberg. From this perspective, we need to look at different aspects of inclusion and how ICT enhances inclusion in each of them. Employing this to our exclusion cycle, ICT would be employed differently for each dimension of exclusion. We shall discuss some of the impacts of ICT in the different exclusion dimensions.

\subsection{Education}

Lack education is both a contributer to and a resultant of exclusion [13];[22]; [25].As a contributer, an uneducated persons are very likely to be excluded in the job market. They are more vulnerable to poverty and low income status. They Have limited, often distorted or completely ignorant of basic health information, leading to high prevalence of preventable diseases and mortality and they are mainly ignorant of their civic rights. Excluded persons may lack access to education either as an individual or as a community. Indeed, access to education and training has been identified as the best way in providing economic inclusion [15].The most vulnerable includes the poor, people who cannot pay for the education. Even when there is free basic education like in Kenya, quite a number of children are locked out for lack of uniform, or the schools are at a distant. Public schools offering the free basic education may lack facilities thus undermining the quality of education given. Cultural barriers like pastoralist, gender inequality practices and religion and myths may also inhibit access to education. Others may include age, disability, regional and geographical barriers among others.

Although many strategies have been employed to ensure education is accessed by many, the integration of ICT in education has broken many barriers than have been anticipated. ICT have bridged the gap in distance education, enabling lecturers and teachers give live class sessions to students who are continents apart. Money that could be used to hire teachers to teach different groups could be used to higher acquire other educational resources. ICT have also enabled easier coordination between teachers, parents and students. Parents can get instant updates should something happen to their children. Parents can easily consult teachers when assisting students with homework. Students can easily collaborate to do assignments and group work and teachers

\section{Volume 4 Issue 12, December 2015}




\section{International Journal of Science and Research (IJSR) \\ ISSN (Online): 2319-7064}

Index Copernicus Value (2013): 6.14 | Impact Factor (2014): 5.611

are able to exchange notes and benchmark thanks to ICT. By availing education online, those who could not attend physical schools can now access education. Online libraries or mobile digital libraries can be used for pastoralist communities. Farmers in rural areas can access agricultural extensive education on their mobile phones without the need to travel to the cities. Virtual labs, animations and computer games are being used to simplify learning. This is helpful especially where resources are scarce. It also helps promote student centered learning and have been shown to increase the learning ability for slow learners. ICT have also been employed to assist learning for children with special needs. As such ICT by promoting education

\subsection{Geographical Location Related Exclusion(GLRE)}

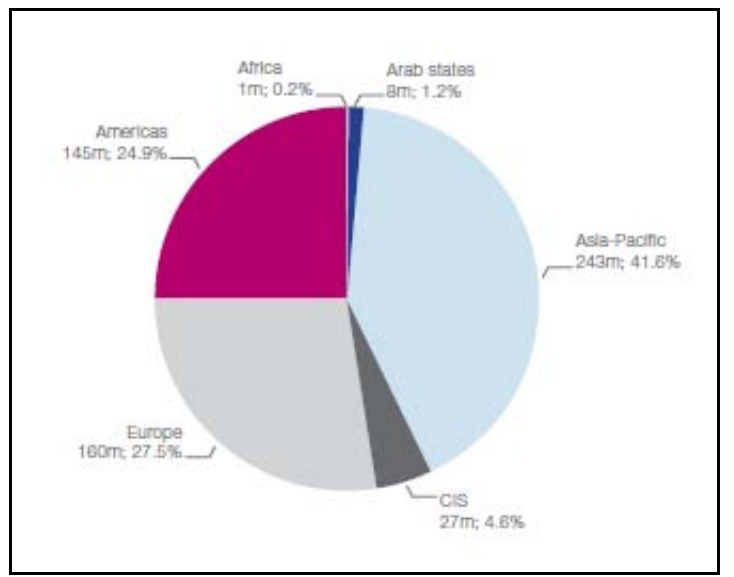

Figure 2: Global Fixed Broadband Subscriptions, 2011. Source: [24]

Where one is, resides can directly or indirectly enhance their chances of being excluded or included. At a global level for instance, chances of one accessing fixed broad band internet in Africa are very slim as compared to being in America [24] see fig 2. This means people living in Africa are more likely to be excluded from broadband benefits. Again, as can be deduced from Fig 3 shows that if born a woman and in Africa or Asia, one is likely to be Excluded in attaining tertiary education compared to a woman born or residing in North America or Europe. At the local level, proximity to urban centers is an important factor in accessing services.

GLREs may be caused by physical barriers like mountains, rivers etc. They may also result from poor infrastructure, transport, health and education facilities, proximity to government services etc. some of the effects of GLRE's include rural urban migrations especially for youths seeking employment. This precipitates to other forms of exclusion where for instance the elderly being left alone with scarce resources and no one to take care of them. Other effects are lack of access to market information especially for the rural farmers, leading to poor farming practices that are less productive.

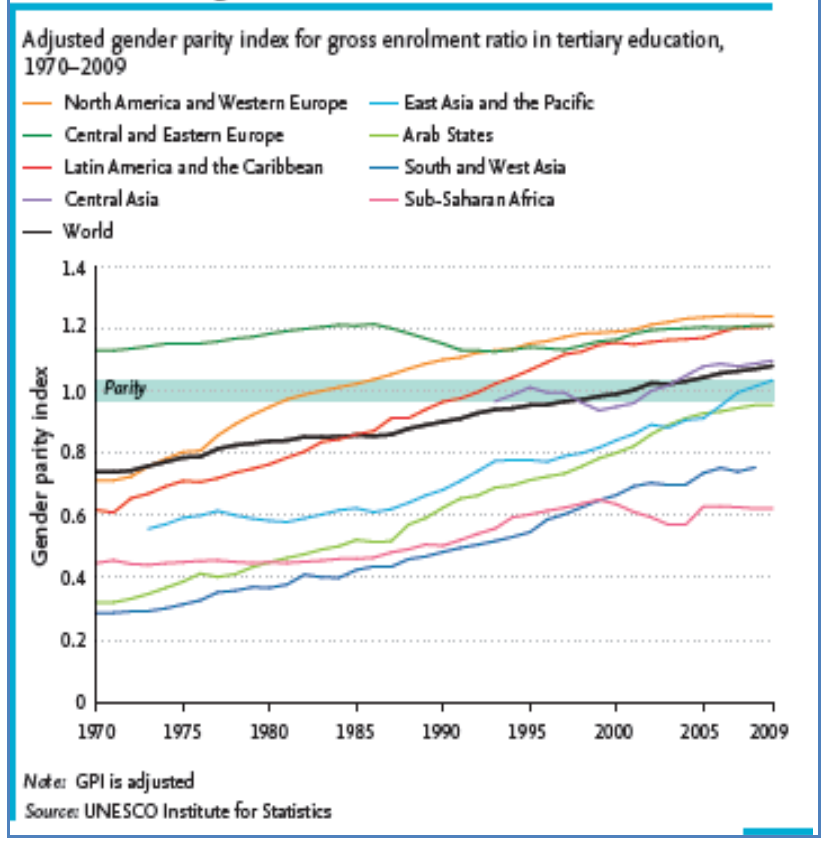

Figure 3: Global GPI for different parts of the world.

Since the ultimate goal of social inclusion is -..to enable people to improve their own lives through the realization of opportunities..." [13], ICT can and often have played a very significant role to reduce the vulnerability of those living in geographically excluded areas. Whenever properly designed and used, ICT have availed opportunities in abundance. Mobile phones have provided means to access news and information in remote areas. Mobile phones need not be connected to power source while in use. This makes them ideal for remote areas. The availability for cheaper solar gadgets with ability to charge mobile phones has helped improve the situation. The emergence of the social media keeps youth and community at large instantly updated on the happenings around the world. Social media also helps people form networks that may be useful in finding employment or market for products. People are as well able to participate in political debate, providing them with a chance to be well informed when making political decisions.

Through ICT, people in the remotest areas can today access education through e-learning. Access to books and journals online, some of which are free, helps improve the quality of education in the excluded places. Innovations like Mpesa in Kenya have enabled small scale farmers and business in rural areas access financial services. Complex messaging services like whatsapp are providing cheap communication services. Electronic commerce has enabled people in remote areas and in third world countries compete for global jobs and market. This goes a long way in curbing unemployment for the youth and in turn reducing crime.

E-governance avails public services to the citizens in every corner of the country. In Kenya for instance, Huduma Centers are aimed at providing one stop shop for government services. This will save citizens time and resources. Citizens will to have to travel to access services that were only availed at the capital city. 


\section{International Journal of Science and Research (IJSR) \\ ISSN (Online): 2319-7064 \\ Index Copernicus Value (2013): 6.14 | Impact Factor (2014): 5.611}

ICT basically provide, compliments and supplements different infrastructures, enabling services that would otherwise not be availed in some of the excluded areas

\subsection{Employment}

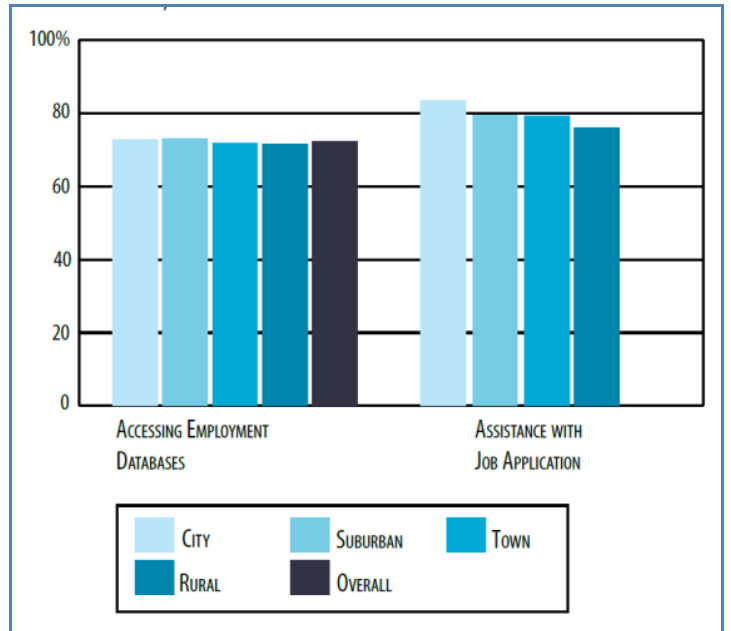

Figure 4: Use of internet in job application. Selected Economy and Workforce Programs Offered by Libraries to Patrons, 2013

Source: [28].

The first time social exclusion was used in relation to human welfare, it was mainly associated with unemployment [12]. - .. The issue of exclusion ...particularly focused on the inability to participate in the ... the labor market, with the associated benefits of social protection..." according to [9] after world war II, $\ldots$. Due to the end of salarial society ${ }^{6}$, a great quantity of individuals transits from stable work to an intermediated zone of social vulnerability, and from there to an even worse situation, which he calls defiliation'...". Just like education, unemployment can result from or cause other forms of exclusion or both. Barriers to employment include -..education level, family and income poverty, gender, lack of prior experience, or shortage of employment options in a community..." [26] Unemployment denies one the economic power. Employment also provides one with social networks that may help one to overcome other exclusion status.

ICT has played a big role in helping people get employed [27]. A sizable number of the users of the internet are either looking for jobs or applying for jobs online. Internet has provided a simpler, convenient and a cheaper way for individuals to apply for jobs. One of the major uses of digital libraries is actually job applications [28]. Fig4 shows the use of internet in seeking jobs is as important for city as it is rural residents. About, 10 years ago, applying for a job in the Kenya public service would require one to send several copies of their resume and certificates. A process that was costly especially for new graduates especially from poor families and from rural areas. Thanks to the internet, all one needs to do today is to visit their site at http://www.psckjobs.go.ke, sign up and fill in your details. The papers will be required only if you are short listed. This clearly provides an opportunity for many who would otherwise not apply for the jobs though qualified.
Digitization, in the global economy, is a better tool that policymakers can use to spur economic growth and employment [29]. While people from underdeveloped economies have suffered unemployment for long, globalization and digitization have seen -.emerging and developed economies are focusing on innovation, competing globally for talent, resources, and market shares..." ICTs have enabled youths from this countries to provide cheap programming skills without having to travel abroad.

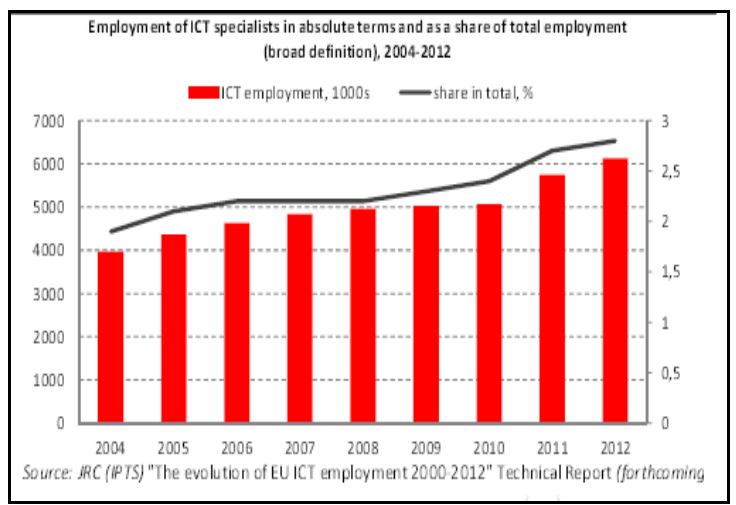

Figure 5: Employment created in the ICT industry

ICT as a field also continues to create direct jobs. Fig 5 shows the trend in numbers of ICT specialist employed from 2004 to 2012 [30]. Clearly the jobs keep on increasing each year. Digital jobs provide unique employment opportunities for people who face barriers to employment [26]. It can also be used to promote self employment, establish business and create jobs for others as well. It's also used to promote economic activities like farming in remote areas. Below is an example of a real life case among the many where ICT has helped create employment for the less privileged.

-..Forty-four-year-old Aicha Moussaif has an entrepreneurial spirit. A mother of four, Aicha never completed high school, but made and sold knit and embroidered goods to support her family. Fueled by a desire to learn, Aicha enrolled in the Women in Technology program where she learned many skills including word processing, database management, spreadsheet management, presentation development, and blogging. After completing the training, Aicha felt more confident and self-sufficient in her use of computers. Using her new IT and entrepreneurship skills, Aicha created a blog from which she sells her embroidered goods to new markets..." [26]

By helping create jobs, ICT increases both the individual's purchasing power, enable them to access good health care, afford good education and ultimately fight poverty.

\subsection{Others}

There are numerous other areas where ICT have been instrumental in ensuring inclusion for the marginalized. This includes political inclusion, aiding people with disability, health systems and e governance among others. Equal access to internet and information services is today a necessity as most services go online. As such, the technology has been viewed as a remedy to the social economic problems [31]; [32] in both developing and developed world's societies [19]; [20]. There has been a major emphasis on the link

\section{Volume 4 Issue 12, December 2015}




\section{International Journal of Science and Research (IJSR) \\ ISSN (Online): 2319-7064}

Index Copernicus Value (2013): 6.14 | Impact Factor (2014): 5.611

between broadband infrastructure and economic growth by developed Governments [33]. Riddlesden and Singleton [33]. also asserts that previous studies estimated that broadband infrastructure accounted for $9.53 \%$ of the United Kingdom's GDP growth in the period 2002 to 2007 [34].Mean while The adoption of increasingly powerful cell phones across the developing world has been an unexpected phenomenon that is now changing the very nature of dealing with poverty and inequity" [18][19]. Development agents have advocated e-governance as an effective way to achieve sustainable development and social inclusion [25]. It's the United Nations view that - ...Egovernment, in improving public service provision and delivery, and in promoting inclusion -with due regard to the needs of vulnerable populations - can be instrumental in mitigating the effects of exclusion and improving people's livelihoods..." [25] Clearly, ICT is playing a significant role in social economic development.

\section{Digital Exclusion}

In the preceding sections, I have argued on the role of ICT in enhancing different forms of inclusion (or curb exclusion.) as such, ICT is itself becoming a basic necessity in life; Necessity in terms of access, use and benefit from it. A new form of exclusion thus is emerging. Digital exclusion is suffered by those unable to benefit from ICT. -. Those unable to access the affordance of technologies are, disadvantaged, marginalized in society ..." [35] it requires resources access and use ICT. In Fig 6, during the first years of the information society age, while in USA the ownership of Computers for every 1000 people moved from slightly over 300PCs to 500 PCs in a period of five years that of African continent remained consistently almost at zero ownership .The irony is those already included are better placed to enjoy the benefits that the Technology bears. The poor, those living with disability, the uneducated and those in remote more often find themselves limited on how much they can access and use ICT. This is likely to widen the social and economic gap between those who have and those have not.

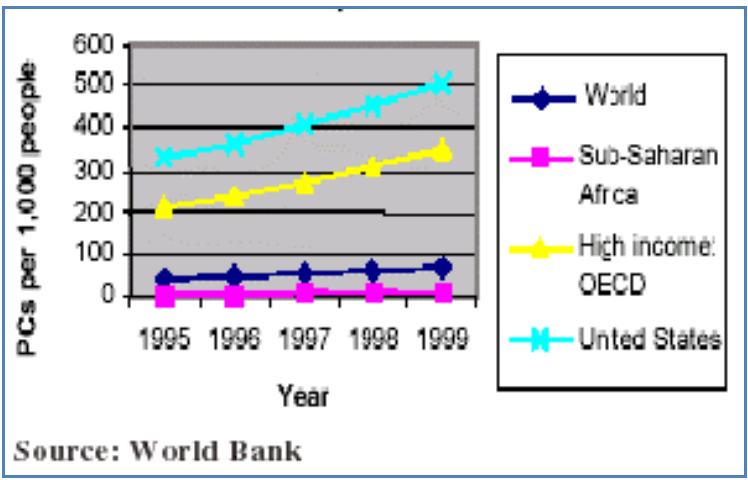

Figure 6: The ownership of computers at the early years of information society

Digital exclusion may manifest itself in different ways. At the access level, the cost of ICT facilities may be inhibiting for the poor. Those from the poor countries or remote areas may be locked out due to lack of ICT infrastructure. Other secondary resources like reliable power supply may also be a barrier [36]. Another access level challenge is the type and quality of technology available. The poor may not access the latest technology. The internet speeds in developing countries are on average very low. While many countries in Africa could be employing old PCs in schools for giving occasional computer studies to the pupils, schools in first world countries are having fully computerized classrooms complete with Virtual learning environments and integrating ICT in teaching and learning for different subjects. Special efforts should be made by relevant authorities to make the technology available, accessible and affordable.

At the usage level, ICT requires special skills. The skills can be learned formally or through experience. Education is critical in gaining the required skills. Those with low education levels are often limited in the extent to which they can use and benefit from ICT. Another barrier to usage is language. Most ICT platforms are in foreign language. This increases the learning curve for some communities as one is required to learn the language as well as the skills. The design of the information systems or digital platforms is sometimes unusable. Availing technology only is thus not a solution for digital exclusion. Efforts to avail digital skills for the community are critical. ICT based services should also be designed and availed in a form understandable and usable to the intended consumer.

At the benefit level or the empowerment, those who cannot use ICT are likely to be excluded from benefiting from the technology. If one cannot use the ATM for instance, he or she may be forced to travel long distances, can only access services at certain times and is likely to be charged expensively for the services.

\section{Perceived Model}

From the literature available, ICT is clearly an important tool in fighting poverty and exclusion [37]. Literature also shows that one form of exclusion leads to another form of exclusion forming an exclusion chain. To have individuals or groups included, the right links the exclusion in the chain must be identified and each of them mitigated accordingly. A link in the exclusion chain represents a form of exclusion. Each form of exclusion would need a unique set of ICTs and their applications in mitigating it. Educational association may require an e learning platform. Mobile banking would be helpful to a small scale farmer in rural areas.

The Spanner and Nut model envisions the society held together by people just as a system is held together by Nuts. Excluded individuals are seen as loose nuts in the system that requires to be fixed. In this model, the head of the nut is a polygon whose number of sides represents the different forms of exclusions that the individual is vulnerable or exposed to; Sort of the number of links in his exclusion chain.

\section{Volume 4 Issue 12, December 2015}




\section{International Journal of Science and Research (IJSR) \\ ISSN (Online): 2319-7064}

Index Copernicus Value (2013): 6.14 | Impact Factor (2014): 5.611

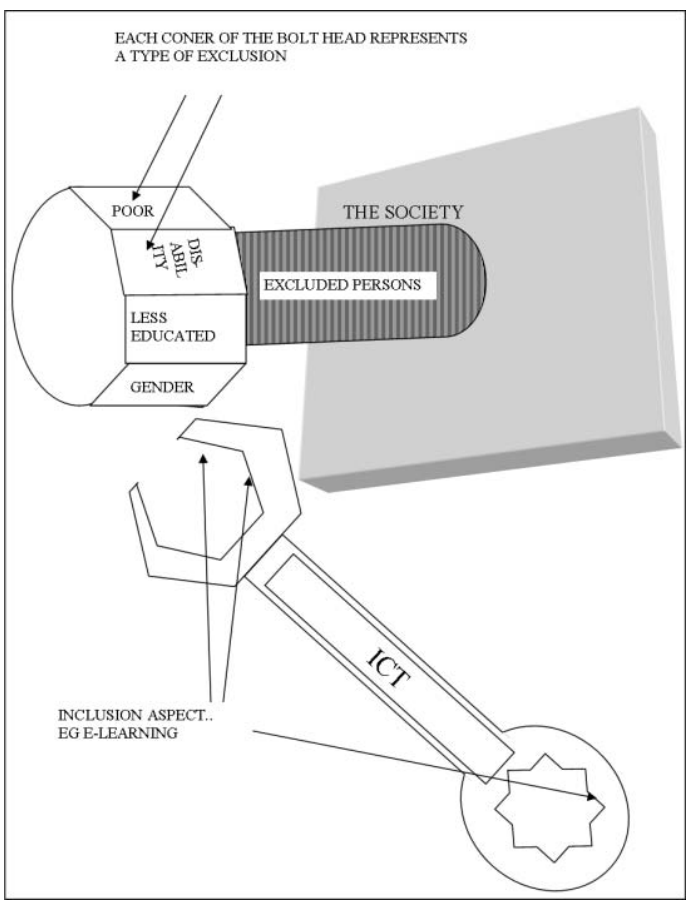

Figure 7: Authors Perceived Spanner and Nut Model of the Role of ICT in Social Inclusion

The ICT is the spanner used to screw and tighten back the Nut into the system (enhance inclusion). Each bolt requires the right spanner. The size and type of the spanner is dependent on the size and shape of the Nut's head. Just like the type of ICT and how it is used should be determined by the form of inclusion we want to achieve. Using the wrong spanner in the work may spoil the Nut and even loosen it further. Just as using the wrong technology or using it wrongly may lead to further exclusion. In other words, it's not how the having the spanner that fixes the Nuts, it's how well they are used that does the job and so are the ICTs.

\section{Conclusion}

The paper looked at the social inclusion/exclusion discourse. Unlike Earlier approaches, Social inclusion is multidimensional and seeks to create an inclusive society. A society that - . rises above differences of race, gender, class, generation and geography..." ensures equal opportunity no matter where one comes from. From the literature, there are many form of exclusion. One form of exclusion leads to another. This may lead to an exclusion cycle. Social inclusion may require a strategy to break or reverse the cycle. Knowing where to break the cycle is critical. ICT is playing a big role to enhance social inclusion. but the technology has to chosen right and applied right for the right results, just like a nut and a spanner. Lack of access to the right technology by some is also leading to a new form of exclusion. The digital Exclusion"

\section{References}

[1] Greenberg A, 2005, ICTs for Poverty Alleviation: Basic Tool and Enabling Sector. Sida, ICT for Development Secretariat, Department for Infrastructure and Economic Cooperation, Article number: SIDA4937en, ISBN 91586-8429-8
[2] Pradhan, R. (2006). Understanding Social Exclusion and Social Inclusion in the Nepalese Context: Some Preliminary Remarks. Understanding Social Inclusion and Exclusion: Theories Methodologies and Data", (pp. 1-17). Kathmandu

[3] UN. (2010). Analysing and Measuring Socia l Inc lusi on in a Globa l Conte xt. United Nations, Department of Economic and Social Affairs. NEW YORK: United Nations publication.

[4] Sinclair, S., Bramley, G., Dobbie, L., \& Gillespie, M. (2007). SOCIAL INCLUSION AND COMMUNICATIONS: A REVIEW OF THE LITERATURE. Ofcom Consumer Panel.

[5] Donna Vaughan(2013): Terms Of Inclusion: Discriminatory Development Policy

[6] Sen, A. (2000). Social Exclusion: Concept, Application and Scrutiny" in Social Development Paper No. 1, Asian Development Bank

[7] Allman, D. (2012, jan-marh). The Sociology of Social Inclusion. sage open, pp. 1-16.

[8] Westfall, R. (2010). Dimensions of Social Inclusion and Exclusion In Yukon, 2010. Yukon Bureau of Statistics, Office of Social Inclusion, Department of Health and Social Services. Yukon Bureau of Statistics.

[9] Steyn J and Johanson G(2011) ICTs and Sustainable Solutions for the Digital Divide: Theory and Perspectives. Information Science Reference (an imprint of IGI Global), New York

[10] The charity commission. (2001). The Promotion of social inclusion. crown.

[11] Karume, S. M., \& Mbugua, S. (2012). Trends in Adoption of Open Source Software in Africa. Journal of Emerging Trends in Computing and Information Sciences , 3 (11), 1509-1515

[12]A. B. Atkinson and E. Marlier, 2010, Analyzing and Measuring Social Inclusion in a Global Context, Department of Economic and Social Affairs of the United Nations

[13]UN Volunteers, 2012, Volunteerism and Social Inclusion, An extract from the 2011State of the World's Volunteerism Report. ISBN: 978-92-95045-60-6

[14] Rawal. N., 2007, Social Inclusion and Exclusion: A Review, Dhaulagiri Journal of Sociology and Anthropology $2,161-180$

[15] Canada, senate report,2013, In from the Margins, Part II: Reducing Barriers to Social Inclusion and Social Cohesion. The Standing Senate Committee on Social Affairs, Science and Technology Senate, Ottawa, Ontario, Canada, K1A 0A4.This report can be downloaded at: www.senate-senat.ca/social.asp

[16] Nyambura M. and Waema T M (2011) Development outcomes of internet and mobile phones use in Kenya: the households' perspectives. Emerald Group Publishing Limited

[17]Zheng W. and Stahl B. C. . (2011). Technology, capabilities and critical perspectives: what can critical theory contribute to Sen's capability approach? Ethics and Information Technology , 13: 69-80.

[18] Smith, M. t., Spence, R., \& Rashid, A. T. (2011). Mobile Phones And Expanding Human CAPABILITIES. Information Technologies\& International Development , 7 (3), pp. 77-88. 


\section{International Journal of Science and Research (IJSR) \\ ISSN (Online): 2319-7064}

Index Copernicus Value (2013): 6.14 | Impact Factor (2014): 5.611

[19]Mitrovic .Z(2013). E-social Astuteness skills for ICTsupported equitable prosperity and a capable developmental state in South Africa. International Journal of Education and Development using Information and Communication Technology (IJEDICT), 9(3). 103-123.

[20] Yihua Yang et al(2013) Roots of Tomorrow's Digital Divide: Documenting Computer Use and Internet Access in China's Elementary Schools Today. China \&World Economy /, 21(33)61-79

[21] Visser, Marijke (2013). "Digital Literacy and Public Policy through the Library Lens."Maine Policy Review 22.1: $104 \quad-113$, http://digitalcommons.library.umaine.edu/mpr/vol22/iss $1 / 27$.

[22] Liisa, 2008, The effects of ICT on school: teachers ' and students “ perspectives, ISBN 978-951-29-3684-7

[23] Canada, senate report,2013, In from the Margins, Part II: Reducing Barriers to Social Inclusion and Social Cohesion. The Standing Senate Committee on Social Affairs, Science and Technology Senate, Ottawa, Ontario, Canada, K1A 0A4.This report can be downloaded at: www.senate-senat.ca/social.asp

[24]ITU, 2012, The State Of Broadband 2012: Achieving Digital Inclusion For All. A Report By The Broadband Commission

[25]UN. (2012). E-Government;E-Government for the People. New York: United Nations, Department of Economic and Social Aff airs.

[26] KARIM HARJI, et al,2013, Digital Jobs; Building Skills for the Future. The Rockefeller Foundation. http://www.rockefellerfoundation.org/uploads/files/9c9e 4885-68e6-4670-9d48-11a830f92401-website.pdf

[27] Ellen Johanna Helsper, 2012, A Corresponding Fields Model for the Links between Social and Digital Exclusion. Communication Theory 22 , 403-426, ISSN 1050-3293

[28] Bertot, J.C., Jaeger, P.T., Lee, J., Dubbels, K., McDermott, A.J., Real, B. (2014). 2013 Digital Inclusion Survey: Survey Findings and Results. College Park, MD: Information Policy \& Access Center, University of Maryland College Park. Available at http://ipac.umd.edu/.

[29] World Economic Forum, 2013, The Global Information Technology Report 2013; Growth and Jobs in a Hyper connected World. ISBN-10: 92-95044-77-0 ISBN-13: 978-92-95044-77-7. www.weforum.org/gitr.

[30] European Commission 2014, Digital Inclusion and Skills; Digital agenda score Card

[31] Alshehri . M, Drew .S \& Alfarraj .O (2012). A Comprehensive Analysis of E-government services adoption in Saudi Arabia: Obstacles and Challenges.(IJACSA) International Journal of Advanced Computer Science and Applications, 3(2), www.ijacsa.thesai.org

[32] Animashaun1J. O et al(2014),Patterns and Drivers of Mobile Telephony for Sustainable Livelihood among Farming Households in Kwara State, Nigeria .Journal of Agricultural Informatics . 5, (2),34-44. ISSN 2061862X (http://www.magisz.org/journal) 34

[33] D and Singleton A. D(2014). Broadband speed equity: A new digital divide? Elsevier,Applied Geography 52 (2014) http://dx.doi.org/10.1016/j.apgeog.2014.04.008 0143 6228/Crown Copyright _ 2014 Published by Elsevier Ltd

[34] Koutroumpis, P. (2009). The economic impact of broadband on growth: a simultaneous approach. Telecommunications Policy, 33(9), 471e485.

[35] Seale J. 2009, Digital inclusion, A Research Briefing by the Technology Enhanced Learning Phase of the Teaching and Learning Research Programme, University of Southampton, December 2009

[36] Wyche and Murphy, 2013, Powering the Cellphone Revolution: Findings from Mobile Phone Charging Trials in Off-Grid Kenya. CHI'13, ACM 978-1-45031899-0/13/04

[37] Alexander Flor (2014): ICT pathways to poverty reduction: empirical evidence from East and Southern Africa, Information Technology for Development, DOI: $10.1080 / 02681102.2014 .923595$

\section{Author Profiles}

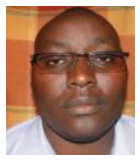

Mr. Muchiri M. Njoki was born at Kiambu in Kenya on $13^{\text {th }}$ February 1977 . He is a $\mathrm{PhD}$ candidate in Information Technology at Kibabii University in Bungoma County (Kenya). He has an MSc (Computer Based Information Systems) from University of Sunderland (UK) and a BEd (Science) from Kenyatta University, Nairobi (Kenya). He is an assistant lecturer, Information Technology department and the Deputy Director E-Learning Center at Dedan Kimathi University of Technology (DeKUT), Nyeri (Kenya). He has also been a Mathematics and Physics teacher. Mr. Muchiri's research interests include, digital inclusion, ICT for Development, and Education and ICT. Mr. Muchiri is a member of the Internet Society Kenyan Chapter.

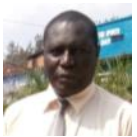

Dr. Franklin Wabwoba is a Senior lecturer in Information Technology and Dean of the School of Computing and Informatics at Kibabii University (Kenya). He holds a PhD (Information Technology) from Masinde Muliro University of Science and Technology, Master of Science (Computer Applications) from Kenyatta University; Endorsement (Educational Management) from University of South Africa and Bachelor of Education (science: Mathematics and Computer Science) from Egerton University. He has taught Computer Science and Information Technology courses for many years. He has ICT industrial experience having worked with Mumias Sugar Company. He has presented several papers in scientific conferences and has many publications in referred journals as well as university level computing books. He has a strong research interest in green ICT, the impact of ICT applications on the community and integration of ICT into education. $\mathrm{He}$ is a professional member of the Association for Computing Machinery (ACM). 